\title{
Уехать "куда" или "откуда": условия жизни и миграционные стратегии жителей дальневосточного российско-китайского приграничья
}

Приграничье - это весьма специфичное территориальное образование, поскольку испытывает существенное влияние государственной границы, выполняет особые функции. В качестве эталонных характеристик приграничных регионов следует обозначить, в первую очередь, равномерное заселение и равномерное развитие, нужно не допускать массового оттока населения и запустения территорий. Кроме того, должна осуществляться целенаправленная политика в отношении защиты границы посредством фрормальных и неформальных социальных структур и институтов, включая организацию дееспособных местных сообществ, воспитание патриотизма и других идейно-нравственных ценностей. Не менее важным является обеспечение достойного уровня социально-экономического развития приграничных территорий, стимулирование благоприятных условий для жизни местного населения.

Мы полагаем, что стремление, а в перспективе и достижение отмеченных характеристик будет свидетельствовать о жизнеспособности приграничных регионов. Таким образом, приграничье должно проектировать "своё" пространство, всячески способствовать объединению людей, а также формировать эффективные жизненные стратегии местных сообществ, включающие в себя фрактор присутствия границы. Поскольку на сегодняшний день положение приграничья как некоего форпоста страны всё более и более актуализируется, соответственно, имеется определённая потребность в исследовании социальных процессов, происходящих в приграничных регионах.

Являясь ключевым социально-демографическим процессом, миграция выступает объектом исследования многочисленных теоретико-методологических концепций. В основе данных подходов лежит понимание миграции как френомена, имеющего преимущественно диналичные свойства, на которые оказывают влияние различные фракторы. В то же время, говоря о приграничье как особой территориальной зоне, важно учесть именно статический аспект, который гарантирует стабильность развития территории и её неприкосновенность. Большинство же исследований направлены либо на изучение приграничных территорий (в статике), либо миграционные процессы (в динамике). Рассмотрим основные подходы, сложившиеся в настоящее время в практике анализа данных феноменов.

Современные исследования приграничной проблематики базируются на фондаментальной теоретико-методологической базе, сформированной представителями различных наук: фрилософии, социологии, этнографрии, демографии, политологии и др., а также на результатах эмпирических исследований. Одним из наиболее популярных в контексте изучения трансгранич-

(C) Винокурова А. В., Ардальянова А. Ю., Шаривхан Ж., 2020

ВИнОКУРОВА Анна Викторовна, канд. социол. наук, доцент департамента социальных наук Дальневосточного федерального университета (2. Владивосток). E-mail: vinokurova77@mail.ru

АРДАЛЬЯнОВА Анна Юрьевна, канд. социол. наук, доцент департамента социальных наук Дальневосточного федерального университета (2. Владивосток). E-mail: ardy2004@mail.ru

ШАРИВХАН Жарденбек, Ph.D., старший преподаватель кафедры юриспруденции Кокшетауского государственного университета им. Ш. Уалиханова (е. Кокшетау, Республика Казахстан). E-mail: sharivkan@mail.ru 
ных взаимодействий является геополитический подход. Он рассматривает изучение границ с точки зрения конкретного географического и политического разделения границ [см. подробнее: 21; 22; 24].

Подход сторонников теории ращионального выбора предполагает изучение деятельности бизнес-структур, что делает возможным его применение к анализу приграничного (трансграничного) взаимодействия структур управления, бизнеса, образования и пр. [см. подробнее: 26]. Концепция фрункционализма в контексте исследования приграничья акцентирует внимание на изучении типов и способов сотрудничества, формировании трансграничных регионов, предпочтений политических элит [см. подробнее: 25].

Между тем многообразие попыток анализа приграничных процессов в междисциплинарном исследовательском поле не раскрывают значения и роли условий жизни, а вместе с тем и миграционных настроений жителей приграничных регионов.

Отмеченные нами теоретико-методологические подходы так или иначе делали попытку анализа приграничных территорий, но при этом не ответили на главный для нас вопрос - какую роль во всех перечисленных процессах играют условия жизни и миграционные настроения "приграничников", каким образом в них участвуют люди, проживающие в приграничных регионах? Анализ феномена миграции в приграничье предполагается осуществлять с опорой на следующие, сложившиеся в исследовательской практике направления изучения миграционных процессов. Одно из них связано с теоретическим осмыслением понятий "миграция" и "миграционные процессы", классификацией основных миграционных потоков, исследованием траекторий движений мигрантов и трансформаций общества под влиянием миграции. В отечественной научной литературе это направление отражено в трудах таких учёных, как Ж.А. Зайончковская, И.В. Ивахнюк, Л.Л. Рыбаковский и др. [см., напр.: $4 ; 6 ; 12]$. Ещё одно направление посвящено проблемам формирования и реализации миграционной политики в России. Существенный вклад в его развитие внесли И.Б. Бритвина, Е.В. Шевцова, Н.А. Ткачева и др. [см. подробнее, напр.: $3 ; 16 ; 23]$.

В целом отметим повышение научного и практико-ориентированного интереса в контексте изучения социального потенциала, әкономического и демографического развития приграничных территорий [см. подробнее, например: $7 ; 2 ; 1 ; 10 ; 17 ; 8 ; 13]$.

Основной целевой установкой нашего авторского исследования является комплексный анализ условий жизни жителей дальневосточного российско-китайского приграничья с последующей оценкой их миграционных стратегий. Для достижения поставленной цели мы опирались на вторичный социологический анализ (в том числе с использованием статистических данных) и количественные методы (анкетирование). В рамках реализации проекта "Жизнь на фрронтире: миграции и мобильности в приграничье" в приграничных населенных пунктах Приморского и Хабаровского краев, Амурской области и Забайкалья нами был проведён анкетный опрос. В связи со сложившейся эпидемиологической обстановкой было принято решение проводить заочное анкетирование. Вопросы анкеты были размещены в Google-фpopмe. Ссылка была разослана потенциальным респондентам. Общий объём выборочной совокупности составил 442 человека $(\mathrm{N}=442)$. Выборка - целевая, квотная (в качестве квотируемых признаков были выбраны пол и возраст), также число респондентов в выборочной совокупности в конкретном регионе определялось пропорционально доле населения с заданными социально-демографическими характеристиками в генеральной совокупности. Основные характеристики выборки в соответствии с квотами можно представить следующим образом: мужчины (203 чел.), женщины (239 чел.); лица в возрасте 18-24 лет (48 чел.), 25-34 лет (99 чел.), 35-59 лет (202 чел.), 60 лет и старше (93 чел.); жители Приморского края (163 чел.), жители Хабаровского края (114 чел.), жители Амурской области (67 чел.), жители Забайкальского края (98 чел.). Метод построения выборки - комбинированный с использованием методов "доступных случаев", "снежного кома", "типичных представителей". Сбор полевых материалов осуществлялся в летний период 2020 года. Исследование носило разведывательный характер, по предварительным итогам мы имеем данные пилотного характера. 
Таблица 1. Среднегодовая численность населения дальневосточных регионов российско-китайского приграничья

\begin{tabular}{|l|c|c|c|c|c|}
\hline \multirow{2}{*}{\multicolumn{1}{|c|}{ Регион }} & \multicolumn{5}{|c|}{ Численность населения (чел.) } \\
\cline { 2 - 6 } & $\mathbf{2 0 1 5}$ & $\mathbf{2 0 1 6}$ & $\mathbf{2 0 1 7}$ & $\mathbf{2 0 1 8}$ & 2019 \\
\hline Амурская область & 807800 & 803700 & 800100 & 795800 & 791619 \\
\hline Еврейская автономная область & 167300 & 165200 & 163100 & 161000 & 159109 \\
\hline Забайкальский край & 1085200 & 1081100 & 1075900 & 1069300 & 1062742 \\
\hline Приморский край & 1931100 & 1926100 & 1918100 & 1907900 & 1899293 \\
\hline Хабаровский край & 1336500 & 1333900 & 1330800 & 1324900 & 1318558 \\
\hline
\end{tabular}

Источник: составлено авторами на основе [9; 11].

В данном контексте следует обратить внимание и на тот факт, что современные процессы социально-демографической и социально-экономической направленности характеризуются динамичным развитием сопредельных с Россией государств Северо-Восточной Азии, в первую очередь, Китая. При этом дальневосточные регионы российско-китайского приграничья, являясь зоной контакта в пространственной интеграции, обладают рядом специфических особенностей. Для Приморья, Хабаровского края, Амурской области, Еврейской автономной области, Забайкалья, так же как и для многих других регионов Дальнего Востока, характерны не совсем благоприятные социальные тенденции, связанные с ухудшением различных аспектов повседневной жизнедеятельности. Продолжается падение уровня жизни населения в целом, а именно: повышаются цены на промышленные и продовольственные товары, сохраняется высокая степень закредитованности, увеличиваются тарифы на услуги жилищно-коммунального хозяйства (ЖКХ), снижаются реальные доходы, растёт число бедных и т.п. Наблюдается и плохое состояние социальной инфраструктуры в регионах дальневосточного приграничья - существенно ограничен доступ хоть к какой-то медицинской помощи, к услугам различных образовательных учреждений (дошкольных, школьных, учреждений дополнительного образования) и пр. Обостряются проблемы в сфере труда и занятости, повсеместное распространение получает дополнительная занятость (наличие у многих людей, помимо основной, работы по совместительству) и отходничество как источник побочного (а зачастую и основного) заработка. Жители приграничья используют разнообразные возможности для занятий личным подсобным хозяйством, охотой, рыбалкой, сбором дикоросов и т.п., что также служит формой самообеспечения и некоторого дохода.

Следовательно, отмеченные негативные тренды отрицательно воздействуют на все стороны социальной жизнедеятельности населения дальневосточного приграничья, и, соответственно, самым неблагоприятным образом отражаются на социально-экономическом и демографическом развитии.

Одним из простых и понятных показателей для самой общей оценки социального благополучия/неблагополучия является демографическая ситуация (слм. табл. 1).

Сведения таблицы 1 показывают, что за последние пять лет число дальневосточников, проживающих в регионах российско-китайского приграничья, уменьшилось практически на 100 тыс. чел. Сокращение численности населения происходит как за счёт естественной убыли, так и за счёт миграционного оттока. Поэтому вопрос о том, как "закрепить" и "сохранить" людей на Дальнем Востоке, продолжает оставаться актуальным, не теряет своей значимости. В последние годы власти всех уровней серьёзно озаботились этой проблемой. Принят ряд конкретных шагов, направленных на развитие человеческого капитала, экономики, социальной сферы и управления, реализуемых в пилотном варианте в Дальневосточном федеральном округе (ДФО). В настоящее время на это нацелен ряд масштабных законодательных инициатив 
Таблица 2. Среднедушевые доходы населения дальневосточных регионов росийско-китайского приграничья

\begin{tabular}{|l|c|c|c|c|c|c|}
\hline \multirow{2}{*}{\multicolumn{1}{|c|}{ Регион }} & \multicolumn{5}{|c|}{ Доходы населения (в месяц; рублей) } \\
\cline { 2 - 8 } & 2015 & 2016 & 2017 & 2018 & 2019 & Место, занимаемое в РФ \\
\hline Амурская область & 28240 & 27976 & 29213 & 30937 & 32799 & 22 \\
\hline Еврейская автономная область & 23759 & 23069 & 23679 & 24696 & 26099 & 52 \\
\hline Забайкальский край & 22014 & 22080 & 22714 & 23992 & 25625 & 57 \\
\hline Приморский край & 31071 & 31265 & 32269 & 34619 & 36489 & 15 \\
\hline Хабаровский край & 35460 & 36565 & 37098 & 39084 & 41337 & 13 \\
\hline
\end{tabular}

Источник: составлено авторами на основе [11;14].

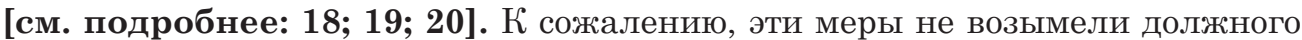
эфрфекта, сокращение численности постоянного населения в регионах дальневосточного российско-китайского приграничья продолжается.

Помимо численности населения ещё одним показателем, существенно влияющим на уровень и качество жизни населения, являются среднедушевые доходы и среднемесячная заработная плата (сл. табл. 2 и табл. 3).

Данные, представленные в таблицах $2 u$ 3, показывают увеличение среднедушевых доходов населения и среднемесячной заработной платы во всех рассматриваемых нами территориальных образованиях. Но, несмотря на наблюдаемый рост данных социально-экономических показателей, сокращается оборот розничной торговли по крупным и средним предприятиям, снижается объём предоставляемых платных услуг. Другими словами, реальные доходы населения уменьшаются, что выступает одним из индикаторов социального неблагополучия. Анализ динамики количества хозяйствующих субъектов показывает, что предпринимательская активность в дальневосточных регионах российско-китайского приграничья также сокращается. В 2018 году в рассматриаемых нами территориальных образованиях число предприятий и организаций снизилось к уровню 2017 года в среднем на 4,6\% [см. подробнеe: 11].

Официальные статистические данные подтверждаются и результатами предпринятого нами социологического исследования, которое также показало, что одной из главных проблем дальневосточных приграничных регионов является бедность. Так, при ответе на вопрос: "Как Вы оцениваете регион, в котором Вы живёте, по сравнению с другими регионами России?", большинство наших респондентов (46,7\%) выбрали вариант "скорее неблагополучный, слаборазвитый"; 16,4\% указали на то, что регион их проживания "бедный, депрессивный, слаборазвитый". Положительную оценку социально-экономического состояния региона дали около трети опрошенных: $26,5 \%$ отметили вариант ответа "скорее благополучный, развитый" и 8,5\% - "социально и экономически благополучный, развитый". При этом наши респонденты дополняли свои ответы такими высказываниями: "регион не развит соииально" (житель Забайкальского края), "очень дорогой регион" (жительница Хабаровского края), "развит хорошо в плане заводов, предприятий и всего такого, но вот жить людял трудно" (житель Приморского края), "потенциал у региона есть, но власти это не используют" (житель Амурской области).

Наблюдаемые неблагоприятные тенденции в сфере регионального социально-экономического развития обусловливают заметные изменения в социальном самочувствии дальневосточников. В своём исследовании мы зафиксировали негативные сдвиги в социальном самочувствии жителей российско-китайского приграничья, для значительной части респондентов характерен высокий уровень тревожности в связи с неопределёнными жизненными перспективами. Стресс, вызываемый бедностью, снижением доходов и отсут- 
Таблица 3. Среднемесячная номинальная начисленная заработная плата работников по полному кругу организаций в дальневосточных регионах российско-китайского приграничья

\begin{tabular}{|l|c|c|c|c|c|c|}
\hline \multirow{2}{*}{\multicolumn{1}{|c|}{ Регион }} & \multicolumn{5}{|c|}{ Заработная плата (в месяц; рублей) } \\
\cline { 2 - 8 } & 2015 & 2016 & $\mathbf{2 0 1 7}$ & $\mathbf{2 0 1 8}$ & $\mathbf{2 0 1 9}$ & $\begin{array}{c}\text { 2020 } \\
\text { (оперативные данные) }\end{array}$ \\
\hline Амурская область & 31803 & 33029 & 39636 & 43156 & 48057 & 52226 \\
\hline Еврейская автономная область & 29868 & 32091 & 34599 & 39797 & 41528 & 47352 \\
\hline Забайкальский край & 30421 & 32710 & 36153 & 40728 & 44399 & 44608 \\
\hline Приморский край & 33218 & 36413 & 38196 & 42026 & 45372 & 50598 \\
\hline Хабаровский край & 37464 & 42476 & 43461 & 46583 & 48887 & 50706 \\
\hline
\end{tabular}

Источник: составлено авторами на основе [15].

ствием возможностей для их повышения усилился настолько, что более половины опрошенных $(51,4 \%)$ выразили желание сменить место жительства.

Из потенциальных мигрантов 5,4\% планируют переехать в другой населённый пункт своего региона, здесь, конечно же, предпочтение отдаётся региональным столицам. У $12 \%$ респондентов в планах переезд в другой регион России, основными центрами притяжения выступают направления, которые условно можно обозначить, как: "Центр" (Москва и прилегающие территории Центрального федерального округа), "Запад" (Санкт-Петербург, Калининград) и "Юг" (Краснодарский край, Черноморское побережье). Ещё 8,7\% опрошенных отметили, что хотели бы переехать в другую страну, чаще других вариантов для эмиграции называли США, развитые страны Западной Европы (Норвегия, Швейцария, Ирландия, Германия, Швеция), государства АТР (Вьетнам, Таиланд, Южная Корея, Япония, Китай, Новая Зеландия).

Очень примечательным фрактом является значительный процент $(25,3 \%)$ тех, кто ещё не решил куда, но хочет уехать. Другими словами, на первый план выступает стратегия не "куда", а "откуда" уехать. Мы разделяем мнение, согласно которому основными фракторами, формирующими негативные миграционные настроения жителей Дальнего Востока, выступают: дороговизна жизни, низкий уровень развития инфраструктуры, низкий уровень доходов, неблагоприятный климат, некомфортность среды, недостаточные возможности для образования детей, отсутствие возможностей для самореализащии, отсутствие возможностей для приобретения жилья [5].

В ходе проведённого исследования мы также выявили, что основными причинами, по которым жители дальневосточного приграничья планируют сменить место жительства, выступают следующие (сл. рис. 1).

Таким образом, в основе миграционных намерений жителей дальневосточного приграничья лежат экономические, материальные, образовательные, медико-социальные и социокультурные составляющие. Суждения наших респондентов ещё раз подтверждают, что по большинству показателей качества жизни Дальний Восток имеет существенное отставание от среднероссийского уровня.

Хотя новые экономические реалии (распространение вторичной занятости, свободной занятости (фрриланса), дауншифтинга, снижение уровня социальной защиты большей части индивидуальных предпринимателей, представителей малого и среднего бизнеса и т.п.) создают и новые мотивации поведения населения в профессионально-трудовой сфере. Однако результаты проведённого нами исследования показывают, что, несмотря на то, что они получили сравнительно широкое распространение, для большей части респондентов определяющими в работе являются другие фракторы: сложность переезда в другую местность, даже если там есть работа; высокая степень зависимости от администрации и работодателей при крайней слабости профрсо- 
Рис. 1. Распределение ответов на вопрос: "По каким причинам Вы планируете сменить место жительства?" (в \% от числа опрошенных)*

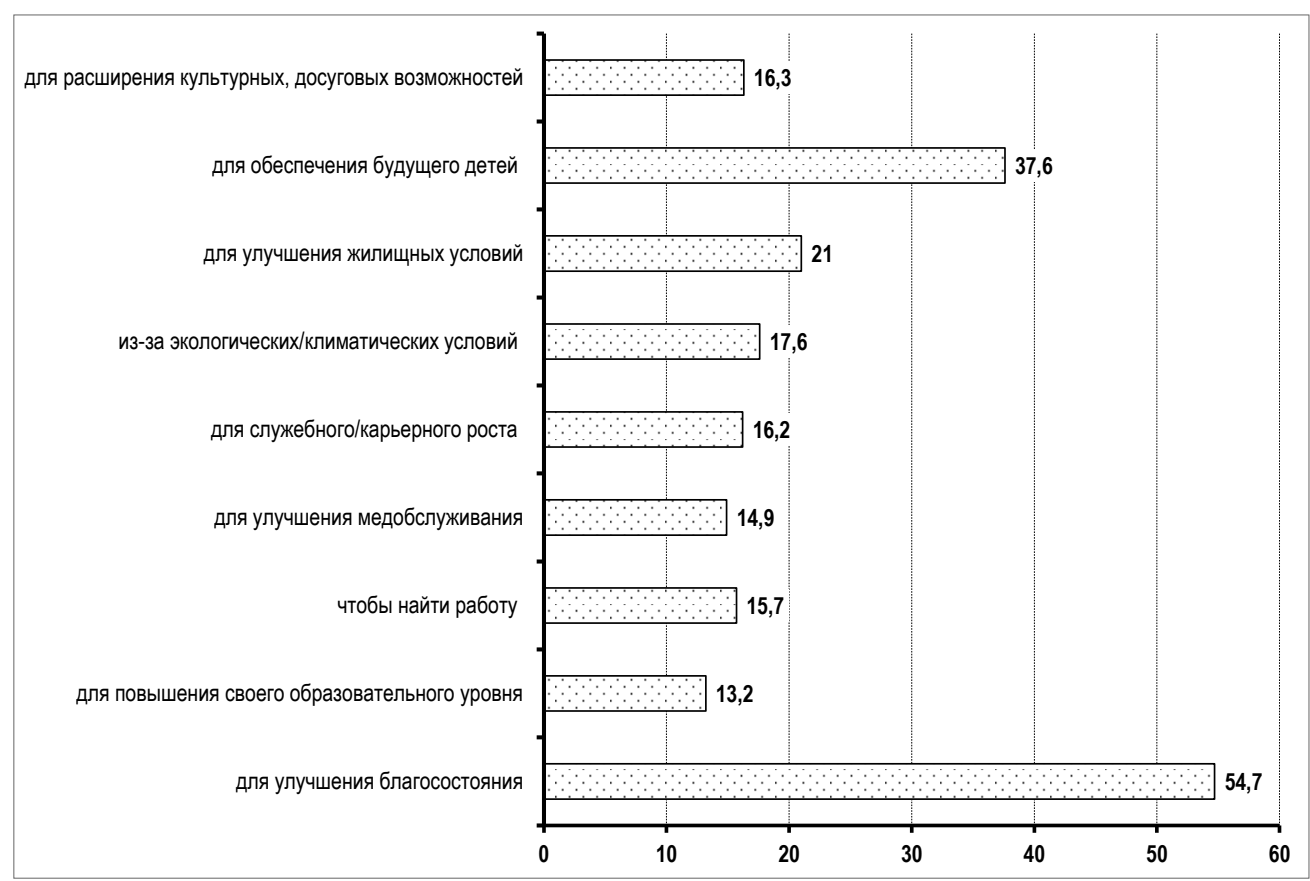

* Сумма больше 100\%, так как допускался выбор нескольких вариантов ответа.

Источник: составлено авторами на основе данных [6; 14].

юзов и т.д. В этих условиях большинство людей вынуждено ценить любую имеющуюся у них работу.

Данное положение подтверждается результатами ответов на вопрос касательно степени удовлетворённости своей работой. При ответе на этот вопрос респондентам было предложено выбрать один из вариантов по 10-балльной шкале, где значение "1" соответствует оценке "совершенно не удовлетворён", "10" - "полностью удовлетворён". Распределение ответов показало, что на практике требования жителей дальневосточного приграничья к работе весьма умеренны. Около половины опрошенных (56,9\%) оценили свою работу положительно (6 баллов и выше), причем $7,6 \%$ указали, что она их полностью удовлетворяет (дали оценку 10 баллов), а ещё 25,3\% респондентов выбрали оценки 4 и 5 баллов, т.е. значения, максимально приближённые к средним. Учитывая современные реалии, в том числе и ситуацию с продолжающим ся распространением коронавирусной инфекции, трудно представить, что у столь значительной части опрошенных работа действительно отвечает всем их запросам. Вероятнее, что на преобладании положительных оценок сказался страх потерять имеющуюся работу, которая позволяет обеспечивать себя и семью. Иными словами, эти данные следует квалифицировать как ещё одно подтверждение того, что на сегодняшний день среди жизненных ориентиров населения дальневосточного приграничья особое место занимает материальное благосостояние. Основная стратегия дальневосточников состоит в том, чтобы удержать имеющиеся ресурсы.

В целом можно заключить, что на сегодняшний день, дальневосточные регионы российско-китайского приграничья испытывают целый ряд трудностей, связанных с проблемами фризического и духовного воспроизводства населения, наличия социальной напряженности, негативными оценками социального самочувствия, усилением миграционных настроений. Акценты в формировании и реализации эффрективной социальной политики должны быть однозначно смещены. Жители Дальнего Востока ждут действенных мер, 
способствующих их собственному закреплению и созданию благоприятных условий жизни для коренных дальневосточников.

\section{Литература}

1. Бережная Л.Ю. Факторы социально-экономического развития приграничных регионов // Вопросы региональной экономики. 2019. № 4 (41). С. 3-7.

2. Бийжанова Э.К. Социальная политика региональной власти: развитие социокультурного потенциала приграничья // Ученые записки Крымского федерального университета имени В.И. Вернадского. Социология. Психология. Педагогика. 2018. T. 4 (70). C. $3-9$.

3. Бритвина И.Б. Миграция и эффективность массовой коммуникации. Екатеринбург: Издательство У ральского университета, 2014. 166 с.

4. Зайончковская Ж.А. Методология и методы изучения миграционных процессов. М.: Центр миграционных исследований, 2007. 370 с.

5. За первое полугодие 2019 года Дальний Восток покинули 6,8 тыс. человек [Электронный ресурс] // MagadanMedia: [региональное подразделение медиахолдинга PrimaMedia]. URL: https://magadanmedia.ru/news/877527/ (дата обращения: 11.11.2020).

6. Ивахнюк И.В. Развитие миграционной теории в условиях глобализации // Век глобализации. 2015. № 1. С. 36-51.

7. Киреев А.А. Модель пограничной политики на российском Дальнем Востоке: факторы и механизмы // Ойкумена. Регионоведческие исследования. 2017. № 3 (42). C. $74-85$.

8. Костина Е.Ю., Орлова Н.А., Панфилова А.О. Социальное благополучие в оценках жителей дальневосточного региона // Вестник Института социологии. 2020. T. 11. № 1. C. 72-85.

9. Оценка численности постоянного населения на 1 января 2020 года и в среднем за 2019 [Электронный ресурс] // Федеральная служба государственной статистики: [веб-сайт]. URL: https://www.gks.ru/folder/12781 (дата обращения: 31.10.2020).

10. Попкова Л.И. Теория и практика приграничных исследований // Геополитика и экогеодинамика регионов. 2019. Т. 5 (15). № 1. С. 243-250.

11. Регионы России. Социально-экономические показатели 2019 [Электронный pecypc] // Федеральная служба государственной статистики: [веб-сайт]. URL: https:// gks.ru/bgd/regl/b19_14p/Main.htm (дата обращения: 10.11.2020).

12. Рыбаковский Л.Л. Миграция населения: прогнозы, факторы, политика. М.: Наука, 1987. 199 с.

13. Спирина А.С., Максимова С.Г. Состояние безопасности и доверия в приграничных регионах России: по результатам социологического исследования // Известия высших учебных заведений. Сощиология. Экономика. Политика. 2020. №2. С. 53-62.

14. Среднедушевые доходы населения, оперативные данные по субъектам Российской Федерации (новая методология) [Электронный ресурс] // Федеральная служба государственной статистики: [веб-сайт]. URL: https://www.gks.ru/folder/13397 (дата обращения: 25.10.2020).

15. Среднемесячная номинальная начисленная заработная плата работников по полному кругу организаций по субъектам Российской Федерации [Электронный pecypc] // Федеральная служба государственной статистики: [веб-сайт]. URL: https:// rosstat.gov.ru/labor_market_employment_salaries (дата обращения: 08.11.2020).

16. Ткачева Н.А., Белоножко М.Л. Миграционная политика и безопасность личности, общества и государства. Тюмень: Изд-во ТюмГНГУ, 2013. 236 с.

17. Троянская М.А., Тюрина Ю.Г. Приграничные территории: понятие, развитие и значение для национальной экономики // Национальные интересы: приоритеты и безопасность. 2020. Т. 16. № 3 (384). С. 431-448.

18. Федеральный закон "О территориях опережающего социально-экономического развития в Российской Федерации" от 29 декабря 2014 года № 473-ФЗ [Электронный ресурс] // КонсультантПлюс: [веб-сайт]. URL: http://www.consultant.ru/document/ cons_doc_LAW_172962/ (дата обращения: 24.10.2020).

19. Федеральный закон "О свободном порте Владивосток" от 13 июля 2015 года № 212-Ф3 [Электронный ресурс] // КонсультантПлюс: [веб-сайт]. URL: http://www. consultant.ru/document/cons_doc_LAW_182596/ (дата обращения: 24.10.2020).

20. Федеральный закон "Об особенностях предоставления гражданам земельных участков, находящихся в государственной или муниципальной собственности и расположенных на территориях субъектов Российской Федерации, входящих в состав Дальневосточного федерального округа, и о внесении изменений в отдельные законодательные акты Российской Федерации" от 01 мая 2016 года № 119-ФЗ [Электронный pесурс] // КонсультантПлюс: [веб-сайт]. URL: http://www.consultant.ru/document/cons_ doc_LAW_197427/ (дата обращения: 24.10.2020). 
21. Хантингтон С. Столкновение цивилизаций. М.: АСТ, 2003. 603 с.

22. Хаусхофер К. О геополитике: работы разных лет. М.: Мысль, 2001. 250 с.

$140 \mathrm{c}$.

23. Шевцова Е.В. Миграционная политика. Новосибирск: Изд-во СибАГС, 2015.

24. Chauprade A. Chronique du choc des civilizations. Paris: Chronique Dargaud Editions, 2013. $271 \mathrm{p}$.

25. Lahteenmaki K. Cooperation of the European Border Regions // Changing European Security Landscape / Ed. by Clive Archer and Olli-Pekka Jalonen. Tampere Peace Research Institute. 1995. Research Report. № 63. P. 270-271.

26. Roberts P.W., Lloyd M.G. Regional Development Agencies in England: New Strategic Regional Planning Issues? // Regional Studies. Journal of the Regional Studies Association. 2000. Vol. 34. № 1. P. 75-80.

\section{Транслитерация по ГОСТ 7.79-2000 Система Б}

1. Berezhnaya L.YU. Faktory sotsial'no-ehkonomicheskogo razvitiya prigranichnykh regionov // Voprosy regional'noj ehkonomiki. 2019. № 4 (41). S. 3-7.

2. Bijzhanova EH.K. Sotsial'naya politika regional'noj vlasti: razvitie sotsiokul'turnogo potentsiala prigranich'ya // Uchenye zapiski Krymskogo federal'nogo universiteta imeni V.I. Vernadskogo. Sotsiologiya. Psikhologiya. Pedagogika. 2018. T. 4 (70). S. $3-9$.

3. Britvina I.B. Migratsiya i ehffektivnost' massovoj kommunikatsii. Ekaterinburg: Izdatel'stvo Ural'skogo universiteta, 2014. $166 \mathrm{~s}$.

4. Zajonchkovskaya ZH.A. Metodologiya i metody izucheniya migratsionnykh protsessov. M.: TSentr migratsionnykh issledovanij, 2007. $370 \mathrm{~s}$.

5. Za pervoe polugodie 2019 goda Dal'nij Vostok pokinuli 6,8 tys. chelovek [EHlektronnyj resurs] // MagadanMedia: [regional'noe podrazdelenie mediakholdinga PrimaMedia]. URL: https://magadanmedia.ru/news/877527/ (data obrashheniya: 11.11.2020).

6. Ivakhnyuk I.V. Razvitie migratsionnoj teorii v usloviyakh globalizatsii // Vek globalizatsii. 2015. № 1. S. 36-51.

7. Kireev A.A. Model' pogranichnoj politiki na rossijskom Dal'nem Vostoke: faktory i mekhanizmy // Ojkumena. Regionovedcheskie issledovaniya. 2017. № 3 (42). S. 74-85.

8. Kostina E.YU., Orlova N.A., Panfilova A.O. Sotsial'noe blagopoluchie v otsenkakh zhitelej dal'nevostochnogo regiona // Vestnik Instituta sotsiologii. 2020. T. 11. № 1. S. $72-$ 85 .

9. Otsenka chislennosti postoyannogo naseleniya na 1 yanvarya 2020 goda i v srednem za 2019 [EHlektronnyj resurs] // Federal'naya sluzhba gosudarstvennoj statistiki: [veb-sajt]. URL: https://www.gks.ru/folder/12781 (data obrashheniya: 31.10.2020).

10. Popkova L.I. Teoriya i praktika prigranichnykh issledovanij // Geopolitika i ehkogeodinamika regionov. 2019. T. 5 (15). № 1. S. 243-250.

11. Regiony Rossii. Sotsial'no-ehkonomicheskie pokazateli 2019 [EHlektronnyj resurs] // Federal'naya sluzhba gosudarstvennoj statistiki: [veb-sajt]. URL: https:// gks.ru/ bgd/regl/b19_14p/Main.htm (data obrashheniya: 10.11.2020).

12. Rybakovskij L.L. Migratsiya naseleniya: prognozy, faktory, politika. M.: Nauka, 1987. 199 s.

13. Spirina A.S., Maksimova S.G. Sostoyanie bezopasnosti i doveriya v prigranichnykh regionakh Rossii: po rezul'tatam sotsiologicheskogo issledovaniya // Izvestiya vysshikh uchebnykh zavedenij. Sotsiologiya. EHkonomika. Politika. 2020. № 2. S. 53-62.

14. Srednedushevye dokhody naseleniya, operativnye dannye po sub"ektam Rossijskoj Federatsii (novaya metodologiya) [EHlektronnyj resurs] // Federal'naya sluzhba gosudarstvennoj statistiki: [veb-sajt]. URL: https://www.gks.ru/folder/13397 (data obrashheniya: 25.10 .2020 ).

15. Srednemesyachnaya nominal'naya nachislennaya zarabotnaya plata rabotnikov po polnomu krugu organizatsij po sub"ektam Rossijskoj Federatsii [EHlektronnyj resurs] // Federal'naya sluzhba gosudarstvennoj statistiki: [veb-sajt]. URL: https:// rosstat.gov.ru/ labor_market_employment_salaries (data obrashheniya: 08.11.2020).

$1 \overline{6}$. Tkacheva N.A., Belonozhko M.L. Migratsionnaya politika i bezopasnost' lichnosti, obshhestva i gosudarstva. Tyumen': Izd-vo TyumGNGU, 2013. 236 s.

17. Troyanskaya M.A., Tyurina YU.G. Prigranichnye territorii: ponyatie, razvitie i znachenie dlya natsional'noj ehkonomiki // Natsional'nye interesy: prioritety i bezopasnost'. 2020. T. 16. № 3 (384). S. 431-448.

18. Federal'nyj zakon "O territoriyakh operezhayushhego sotsial'no-ehkonomicheskogo razvitiya v Rossijskoj Federatsii" ot 29 dekabrya 2014 goda № 473-FZ [EHlektronnyj resurs] // Konsul'tantPlyus: [veb-sajt]. URL: http://www.consultant.ru/document/ cons_ doc_LAW_172962/ (data obrashheniya: 24.10.2020).

19. Federal'nyj zakon "O svobodnom porte Vladivostok" ot 13 iyulya 2015 goda № 212 FZ [EHlektronnyj resurs] // Konsul'tantPlyus: [veb-sajt]. URL: http://www. consultant.ru/ document/cons_doc_LAW_182596/(data obrashheniya: 24.10.2020). 
20. Federal'nyj zakon "Ob osobennostyakh predostavleniya grazhdanam zemel'nykh uchastkov, nakhodyashhikhsya v gosudarstvennoj ili munitsipal'noj sobstvennosti i raspolozhennykh na territoriyakh sub"ektov Rossijskoj Federatsii, vkhodyashhikh v sostav Dal'nevostochnogo federal'nogo okruga, i o vnesenii izmenenij v otdel'nye zakonodatel'nye akty Rossijskoj Federatsii" ot 01 maya 2016 goda № 119-FZ [EHlektronnyj resurs] // Konsul'tantPlyus: [veb-sajt]. URL: http://www.consultant.ru/document/cons_ doc_LAW_197427/ (data obrashheniya: 24.10.2020).

21. KHantington S. Stolknovenie tsivilizatsij. M.: AST, 2003. 603 s.

22. KHauskhofer K. O geopolitike: raboty raznykh let. M.: Mysl', 2001. 250 c. $140 \mathrm{~s}$

23. SHevtsova E.V. Migratsionnaya politika. Novosibirsk: Izd-vo SibAGS, 2015.

24. Chauprade A. Chronique du choc des civilizations. Paris: Chronique Dargaud Editions, 2013. 271 p.

25. Lahteenmaki K. Cooperation of the European Border Regions // Changing European Security Landscape / Ed. by Clive Archer and Olli-Pekka Jalonen. Tampere Peace Research Institute. 1995. Research Report. № 63. P. 270-271.

26. Roberts P.W., Lloyd M.G. Regional Development Agencies in England: New Strategic Regional Planning Issues? // Regional Studies. Journal of the Regional Studies Association. 2000. Vol. 34. № 1. P. 75-80.

Винокурова А. В., Ардальянова А. Ю., Шаривхан Ж. Уехать "куда" или "откуда": условия жизни и миграционные стратегии жителей дальневосточного российско-китайского приграничья.

Для дальневосточных регионов российско-китайского приграничья на сегодняшний день значимы некоторые, не совсем благоприятные социальные тенденции, связанные с ухудшением различных аспектов повседневной жизни людей, включая плохое состояние социальной инфраструктуры, наличие больших трудностей в сфрере труда и занятости, снижение реальных доходов населения и пр. В своём исследовании мы опирались на вторичный социологический анализ (в том числе с использованием статистических данных) и количественные методы (анкетный опрос). В целом выявленные проблемы и тренды существенно влияют на физическое и духовное воспроизводство населения. Их следует учитывать в качестве факторов, воздействующих на социальное условия жизни и миграционные стратегии жителей Дальнего Востока, что является принципиально важным для планирования региональной социальной политики.

Ключевые слова: Дальний Восток, приграничные регионы, региональное развитие, уровень и качество жизни, социальное благополучие, миграционные стратегии

Vinokurova A. V., Ardal'yanova A. YU., SHarivkhan ZH. Leaving "where" or "from where": living conditions and migration strategies of residents of the Far Eastern Russian-Chinese borderland.

For the Far Eastern regions of the Russian-Chinese border to date, some important, not very favorable social trends associated with the deterioration of various aspects of the daily lives of people, including the poor state of social infrastructure, presence of major difficulties in the field of labor and employment, reduced real incomes, etc. In our research, we relied on secondary sociological analysis (including statistical data) and quantitative methods (questionnaire survey). In general, the identified problems and trends significantly affect the physical and spiritual reproduction of the population. They should be taken into account as factors that affect the social well-being and migration strategies of residents of the Far East, which is fundamentally important for planning regional social policy.

Key words: Far East, border regions, regional development, level and quality of life, social well-being, migration strategies

Для цитирования: Винокурова А. В., Ардальянова А. Ю., Шаривхан Ж. Уехать "куда" или "откуда": условия жизни и миграционные стратегии жителей дальневосточного российско-китайского приграничья // Ойкумена. Регионоведческие исследования. 2020. № 4. С. 7-15. DOI: $10.24866 / 1998-6785 / 2020-4 / 7-15$

For citation: Vinokurova A. V., Ardal'yanova A. YU., SHarivkhan ZH. Leaving "where" or "from where": living conditions and migration strategies of residents of the Far Eastern RussianChinese borderland // Ojkumena. Regional researches. 2020. № 4. P. 7-15. DOI: 10.24866/1998$6785 / 2020-4 / 7-15$ 